monalis. Links neben der Art. subcl. dextr. liegt ein kleines Gefäss, dessen Bedeutung ich nicht kenne. - Vergrösserung 70 fach.

Fig. 13. Rechte Hälfte der Schilddrüse eines Embryos von $21,5 \mathrm{~mm} \mathrm{~S}$. $\mathrm{S}$. laterale (IS.) und mediane (mS.) Anlage sind in der Verschmelzung begriffen. - Vergrösserung circa 80 fach.

Fig. 1t. Linke Hälfte der Schilddrüse eines Embryos von $21 \mathrm{~mm}$ S. S. (aus derselben Tracht, wie der von Fig. 13). Die einzelnen miteinander verschmelzenden Zellbalken der medianen und lateralen SchilddrïsenAnlage waren in diesem Präparate distincter, als in dem, das dem vorhergehenden Bilde zu Grunde lag. Das dorsale Ende der IS, mit dem deutlichen Lumen ist aus einem benachbarten Schnitte ergänzt.

\title{
Ueber die Muskelspindeln nebst Bemerkungen über Structur, Neubildung und Innervation der quergestreiften Muskelfaser.
}

Von

Dr. L. Bremer.

Hierzu Tafel XII und XIII.

In den fünfziger Jahren, bis zu Anfang der sechziger drehte sich der Streit über die Bildungsweise der quergestreiften Mnskelfaser vorzugsweise um den ein- oder mehrzelligen Ursprung derselben. Lebert, Remak und Köll iker vertraten den einzelligen Standpunkt, während zu der älteren Schwann'schen Lehre von den Spindelzellen, die sich mit den Spitzen aneinanderreihen und so verschmelzen sollten, Margo's Lehre von den "Sarcoplasten“ trat. Diese sollten in einem kernhaltigen Blasteme entstehen, sich dachziegelartig nebeneinander legen und so verschmelzend ein Primitivbündel bilden; und zwar sollte eine derartige Neubildung nicht 
nur im Embryo, sondern auch im wachsenden und erwachsenen Thiere stattfinden.

Einen neuen Anstoss zu fortgesetzter Discussion der Frage gaben die Untersuchungen We isman n's').

Die Hauptergebnisse dieser Arbeit waren, dass es eine Muskelfaserneubildung im ausgewachsenen Thiere gibt, dass dieselbe theils durch Randabspaltung; theils durch Zweitheilung zu Stande komme, und dass ein phyșiologisches Zugrundegehen von Mutterfasern bei diesem Processe stattfinde.

Obwohl man jetzt in Bezug auf den einzelligen Ursprung der Muskelfaser beim Embryo so ziemlich einig ist, herrscht über die Weismann'schen Angaben immer noch eine beträchtliche Meinungsverschiedenheit. Sie sind theilweise verificirt, theilweise bestritten worden.

$\mathrm{Zu}$ Resultaten, die den Weismann'schen' entgegengesetzt sind, gelangten in neuerer Zeit Petrow sky ${ }^{2}$ ), der die Theilung an ganz entwickelten Muskelfasern bestreitet und meint, die Neubildung misse auf irgend eine andere Weise stattfinden und Ried $\mathrm{el}^{3}$ ), dass das postembryonale Wachsthum der Muskeln allein auf Vergrösserung der bei der Geburt vorbandenen Fasern zurïckzuführen sei.

Die Handbücher drücken sich über den Gegenstand nicht mit Bestimmtheit aus, doch scheinen sie im Allgemeinen Weismann's Auffassung zu begïnstigen.

Der Grund davon, dass die Untersuchungsresultate bei verschiedenen Beobachtern so verschieden ausfielen, liegt wohl vorzugsweise daran, dass man zu oft unterlassen hat, die Jahreszeit, die Thierart und das Alter der Thiere in Rechnung zu bringen. Für eine erfolgreiche Lösung der Frage aber scheint mir die Rücksichtnahme auf diese Punkte und die richtige Auswahl von höchster Wichtigkeit zu sein. Nur so erhält man eine Reihe von histologischen Momenten, die, in geeigneter Weise gesichtet, den ganzen Process der Neubildung und des Wachsthums der Muskelfasern klarzustellen im Stande sind.

1) Ueber das Wachsen der quergestreiften Muskeln nach Beobachtungen am Frosch. Zeitschr. f. rat. Med. 3. Reihe X. Bd. 1861. p. $263 \mathrm{ff}$.

2) Centralblatt für die medic. Wissenschaften. 1873. S. 769.

3) Das postembryonale Wachsthum der Weichtheile. Untersuch. a. d. anatom. Instit. z. Rostock. 1874. 
Ehe die Thatsache anatomisch fest stand, dass eine postembryonale Neubildung von Muskelfasern stattfindet, wusste man durch Zählung, dass ein gegebener Muskel des erwachsenen Thieres mehr Primitivbündel enthält, als der entsprechende eines jungen. $\left.B u d g e^{1}\right)$ unterzog sich der mühevollen Arbeit, die Fasern des Gastrocnemius zu zählen und kam zu dem angeführten Resultate. Da der Gastrocnemius jedoch ein gefiederter Muskel ist, und überhaupt der Zählungsprocess trotz der besten Isolirmethoden immerhin ein schwieriger und weniger zuverlässiger sein dürfte, so kann man diesem Verfahren keine absolut beweisende Kraft beimessen. Riedel's Zählungen weisen keine Vermehrung nach. Der Beweis der Muskelfaserneubildung kann schliesslich doch nur durch directe Beobachtung des Vorganges selbst erbracht werden. Wichtig scheint mir in dieser Beziehung die Arbeit von Rollett zu sein, welcher schon im Jahre 1856 (Wiener Sitzungsber.) nachwies, dass es feine Muskelfäden gibt, welche mit freier Endspitze mitten in Verlauf des Muskelbandes liegen.

Um eine klare Vorstellung von der Neubildung von Muskelfasern im wachsenden Thiere zu erhalten, erachte ich es für nothwendig, ihre Structur in kurzen Umrissen zu beschreiben. Als Typus will ich den Froschmuskel annehmen, einfach aus dem Grunde, weil an diesem die morphologischen Eigenthïmlichkeiten, auf welche es für gegenwärtigen Zweck am meisten ankommt, sich am leichtesten beobachten lassen. Die Angaben haben aber für die quergestreiften Muskeln aller Wirbelthiere Gültigkeit, und es hängt meistens nur von dem Alter der betreffenden Fasern und der Jahreszeit ab, ob sie die gleich zu schildernden Verhältnisse in mehr oder minder ausgeprägter Form aufzuweisen vermögen.

Die Untersuchungsobjecte bildeten Muskelstiickchen, welche sofort nach Tödtung der Thiere mit Goldehlorid behandelt, längere Zeit der Wirkung ameisensauren Glycerins ausgesetzt wurden, doch will ich gleich hier bemerken, dass, wenn man einmal die Goldbilder gesehen hat, man auch an der frischen Muskelfaser die Structureigenthümlicheiten der Hauptsache nach mit Leichtigkeit beobachteu kann.

Mit Max Schultze fasse ich die sogenannten Muskelkerne als Kerne von Muskelkörperchen auf und betrachtet letztere

1) Arch. f. physiolog. Heilkunde N. F. Bd. 2. S. 71. 
als Zellindividuen, die aus einer wechselnden Menge von Zellprotoplasma, Kern und unter Umständen Kernkörperchen besteben.

In älteren Muskelfasern sind die Muskelkörperchen gegen das contractile Gewebe scharf abgegrenzt, arm an Protoplasma, scheinbar unregelmässig zerstreut. In den ältesten Fasern liegen die Kerne in spindelförmigen Aushöhlungen der contractilen Substanz, oft ohne wahrnehmbares Zellprotoplasma. Sie liegen dicht unter dem Sarcolemm, erscheinen manchmal eckig und geschrumpft, wurden von Einigen als dem Sarcolemm angehörig betrachtet und schlechthin Sarcolemm-Kerne genannt, wie man jetzt noch die Kerne der Nervensegmente Neurilemmkerne nennt. Entgegen den Max Schultze'schen Angaben leugnet G. Weber ${ }^{1}$ ) ein die Kerne umgebendes Protoplasma für die Froschmuskeln iiberhaupt. We be r's Behauptung kann sich nur auf die ältesten Muskelfasern beziehen, für welche die oben beschriebenen Verhältnisse obwalten. Es ist sogar möglich, dass hier eine Zellmembranbildung stattfindet, welche ja nach Max Schultze nur auf ein gewisses Alter der Zelle hinweist.

An jüngeren Fasern nun (Fig. 1) zeigen die Muskelkörperchen an beiden Polen ihrer Längsachse deutliche Protoplasmafortsätze; von einer Zellmembran ist nichts wahrzunehmen. Je jünger die Muskelfaser ist, desto deutlicher und länger sind jene Protoplasmafortsätze; am besten wahrnehmbar aber sind sie an den jüngsten Fasern, die nur eine Reibe von Muskelkörperchen anfweisen, welche, meistens längs der Axe des Primitivbündels liegend, rings von contractiler Substanz umgeben sind (vgl. Taf. XII Fig. 15).

Gerlach ${ }^{2}$, welcher diese von ihm ,Zwischensubstanzlinien“ genannten Zellfortsätze mit seinem intravaginalen Nervenplexus in Verbindung bringt, scheint es entgangen zu sein, dass diese Linien, wo sie noch demonstrirbar sind (also in jungen, noch wachsenden Muskelfasern) von Muskelkern zu Muskelkern ziehen, kurz, dass sie die ineinander übergehenden Fortsätze der Muskelkörperchen sind. Diese Zwischensubstanzlinien sind wirkliche Linien oder richtiger Fäden, nicht aber Längsansichten von continuirlichen,

1) Ranvier's Laboratoire d'Histologie. 1874. S. 209.

2) Ueber das Verhältniss der nervösen und contractilen Substanz des quergestreiften Muskels. Arch. f. mikrosk. Anat. Bd. XIII. 
protoplasmatischen, oder, wie Gerlach will, nervösen Scheidewänden, die cylindrisch die Muskelfibrillenbündel umgeben.

Durch Kölliker ist die Auffassung zur Geltung gekommen, dass ein jedes Cohnheim'sche. Feld den Querschnitt eines solchen Fibrillenbündels oder Muskelsäulchens bilde und dass die Begrenzungslinien der Felder die Querschnitte der Protoplasmäntel seien. Es ist aber nie gelungen, auf Querschnitten von Muskelfasern die Querschnitte der Primitivfibrillen in den Cohnheim'schen Feldern zu demonstriren, angeblich, weil sie zu klein seien.

Unterwirft man die frische Muskelfaser (Frosch, Eidechse, Maus) der Gold-Säurebehandlung ${ }^{1}$ ), so erhält man beim Zerzupfen, oft auch durch stärkeren Druck auf das Deckglas unter andern Gewebsfragmenten eine Anzahl Bow m a n n'scher Discs. Dieselben weisen ebenso wie die Querschnitte gefrorener Muskelfasern die Cohnheim'schen Felder auf, wie dies schon Biedermann²), Gerlach ${ }^{3}$ ) und Ranvier ${ }^{4}$ beobachteten. Ferner aber gewahrt man in der Mitte eines jeden Feldes einen Punkt, welcher bis jetzt von den Untersuchern übersehen worden ist. Hin und wieder erscheint derselbe als ein Stäbchen. Bei stärkeren Vergrösserungen (bei Hydrophilus schon mit Hartnack Oc. 3 Syst. VII) gewalurt man radiirende Fäden, die von dem Punkte nach der Peripherie der Felder verlaufen. Die Cohnheim'schen Felder erscheinen in diesem Falle in eine Anzahl kleinerer Felder abgetheilt. Am besten konnte ich die Punkte an Querscheiben durch Maceration zerfallener Muskelfasern von Hydrophilus beobachten (vgl. Taf. XII Fig. 2 d), aber auch an den Muskeln der Amphibien, Reptilien und Säuger sind die mittelständigen Punkte constante Befunde, wenn auch, besonders bei letzteren, die radiirenden Fäden wegen der ausserordentlichen Feinheit derselben nicht immer nachgewiesen werdeu konnten.

Welches sind nun die den Feldern und den Punkten entsprechenden Bilder bei Längsansicht der Muskelfaser?

Betrachten wir die mehrfach erwähnten Protoplasmafortsätze

1) Dieses Archiv.

2) Zur Lehre von dem quergestreiften Bau der Muskelfaser. Wiener Sitzungsb. 1876.

3) 1. c.

4) Leçons sur le système nerveux. 1878 . 
Ueber die Muskelspindeln nebst Bemerkungen über Structur etc. 323

der Muskelkörperchen (Fig. 2 a). Ganz nahe den Kernen erscheinen dieselben als homogene Stränge, etwas weiter werden sie zackig; dann zeigen sie sich als eine Reihe kleinerer, in regelmässigen Abständen stehender, spindelförmiger, rhombischer oder knotenförmiger Körperchen, welche eventuell in Stäbchenform auftreten. Diese Körperchen, ob sie nun als Knötchen oder Stäbchen sich präsentiren, erweisen sich als in regelmässig von einander abstehenden Querfeldern stehend, wie man sich durch verschiedene Tubuseinstellung überzeugen kann. Sie fallen mit den dunklen Querbändern der Muskelfaser zusammen. Sie sind durch Querund Längsfäden unter einander verbunden, so dass je vier die Ecken eines Rechtecks darstellen. Je mehr die Körperchen die Knotenform besitzen, desto deutlicher sind die Quer- und Längsfäden und damit die rechteckigen Figuren, während, wenn sie als Stäbchen erscheinen, ihre Verbindungen oft schwer oder gar nicht erkennbar sind. Im ersteren Falle erscheinen die dunklen Querbänder schmal, die hellen breit, im letzteren sind die dunklen Querbänder breit, die hellen schmal. Die Querlinie im hellen Querbande theilt die Rechtecke in zwei Hälften, eine obere und eine untere.

Die Rhomben- oder Knötchenform kommt durch Schrumpfung ursprünglicher Stäbchen zu Stande. Dieselben schrumpfen nicht gleichmässig und glattkantig, weil dies an den Insertionsstellen der Quertäden nach physikalisehen Gesetzen verhindert wird (vgl. Fig. 2 Schema $f$ und $g$ ). - Je jünger die Stäbchen sind, desto leichter schrumpfen sie und werden zu Knötchen, je älter, desto leichter bewahren sie ihre ursprüngliche Form. Auch die jeweiligen Contractionszustände der Muskelfaser zur Zeit, wo dieselbe zur Behandlung mit Reagentien kommt, spielen hier zweifelsohne eine Rolle.

An Halbqueransichten, wie sich solche hin und wieder an den Schnittenden von Muskelfasern darbieten, erkennt man nun, dass die Knötchenreihen mit ihren Querfäden die Cohnheimschen Felder, von der Kante, gesehen sind. Die Knötchen selbst sind die Kreuzungspunkte der Begrenzungsfäden der Felder. Die Kreuzungspunkte stehen durch Längsfäden auch mit den entsprechenden Punkten der angrenzenden Cohnheim'schen Felder in Verbindung.

Es zieht sich also durch die ganze Muskelfaser 
ein wohldefinirtes Netz, dessen Maschen auf Querschnitten als Fünfecke, bei Längsansicht der.Muskelfaser als Rechtecke erscheinen.

Bei genauerer Untersuchung findet man, dass zwischen den Knötchen oder Stäbchen kleinere derartige Gebilde existiren, welche in derselben Reihe, resp. Ebene, also in den dunklen Querbändern liegen und mit jenen grösseren alterniren. Obwohl ich ihre Querverbindung mit den dickeren Knötchen nicht beobachten konnte, so ist doch ein Zusammenhang mit ihnen wahrscheinlich, wegen der auf den Querschnitten erscheinenden radiirenden Fäden. Die Längsverbindung wird durch deutlich wahrnehmbare Fäden vermittelt. Oft sieht man die Verbindungsfäden sich mit der Krau seAmici'schen Querlinie des hellen Querbandes in der Mitte der Rechtecke kreuzen, wodurch die letzteren in vier Theile zerlegt erscheinen. Die Querlinie verbindet auch die diunnen Fäden untereinander. (Vgl. zu dem Vorstehenden Fig. 1 u. 2 a b ef und g.)

Es giebt demnach in den quergestreiften Muskelfasern alternirende dicke und dïnne Quer- und Längsfäden, alternirende Quer-und Längsreihenvon grossen und kleinen Knötchen, eingröberes und ein feineres Netz.

Obige Darstellung basirt auf Goldpräparaten jungèr Muskelfasern von Frosch, Eidechse und Maus, lässt sich aber auch an frischen, sowie an Ameisensäure- oder Alkoholpräparaten verificiren. Hydrophilus, dessen Muskeln sich schwer vergolden lassen und der sich iberbaupt wegen der ausserordentlichen Dicke seiner Muskelfasern weniger gut zur Demonstration der beschriebenen Verhältnisse eignet und gewisse Structureigenthïmlichkeiten bietet, die für die Wirbelthiere nicht ganz zutreffen, ist nur für die Quernetze verwendet worden, für die Netze bei Längsansicht der Muskelfaser dagegen unberïcksichtigt gelassen.

In Folgendem einige erläuternde! Bemerkungen.

Die Netzbildung lässt sich am besten in der Nähe der Muskelkörperchen der jungen Muskelfasern nachweisen, d. h. da, wo der Differenzirungsprocess am jüngsten ist (Fig. 2a). Je weiter von den Muskelkörpeirchen entfernt, d. h. je älter die differenzirte Substanz ist, desto mebr erscheint sie als die bekannten hellen und dunklen Querstreifen. In alten Muskelfasern, in welchen die Differenzirungsvorgänge beendet sind und die Muskelkörperchen ihr Protoplasma vollständig eingebüsst haben, ist es nur unter 
Ueber die Muskelspindeln nebst Bemerkungen über Structur etc. 325

besonders günstigen Umständen möglich, die beschriebenen Structurverhältnisse zu erkennen.

Die Gerlach'sche Sprenkelung besteht aus Knötchen und Stäbchen, deren Längs- und Querfäden durch Säurewirkung geschwunden oder minder deutlich geworden sind. Ich würde den von $\mathrm{B}$ i e d e r m a $\mathbf{n}$ vorgeschlagenen Namen Strichelung vorziehen. Keineswegs sind dieselben als Fettgranulationen oder als regellos liegende Körner aufzufassen. Nur wo die Muskelfaser gezerrt oder durch Druck lädirt wird, kommt die regellose Anordnung zu Stande. Aber selòst hier kann man sich in den meisten Fällen uberzeugen, dass die Regellosigkeit nur eine scheinbare ist, hervorgerufen durch die Verschiedenheit der Grösse der einzelnen dickeren Knötchen und Stäbchenketten. Sieht man genauer hin, so findet man, dass auch die "Sprenkelungen" zu Reihen angeordnet sind und mit den dunklen Querbändern zusammenfallen. Nie konnte ich die Sprenkelung an ganz jungen Muskelfasern beobachten. Sie kommt an älteren Muskelfasern durch verlängrerte Säurewirkung; wodurch die feineren Stäbchen verblassen und nur die dickeren Knötchen und Stäbchen sichtbar bleiben, zu Stande, ist •also ein Kunstproduct.

Die stärkeren Protoplasmamassen, welche man auf Querschnitten von vergoldeten Muskelfasern hin und wieder zwischen den Cohnheim'schen Feldern eingelagert findet, sind die Querschnitte stärkerer Protoplasmafortsätze der Muskelkörperchen, wie denn auch die Begrenzungspunkte der Felder als Querschnitte von den Zellfortsätzen aufzufassen sind. Den stärkeren Protoplasmafortsätzen begegnet man vorzugsweise an solchen Muskelfasern, bei denen die Muskelkörperchen nicht alle an die Oberfläche gerückt sind, z. B. bei Amphibien und Reptilien.

Bei älteren Muskelfasern von Säugern liegen sie dicht unter dem Sarcolemm. Dass die Begrenzungslinie der Cohnheim'schen Felder nicht die Querschnitte von protoplasmatischen Mänteln sind, geht schon daraus hervor, dass an Muskelfasern, deren Inhalt durch Druck derartig verschoben ist, dass die Ebene der Muskelstäbchenfelder nicht mehr senkrecht, sondern in spitzem Winkel zu dem Längsdurchmesser des Muskelfadens steht, in welchem man jetzt also eine Ansicht theils von der Seite, theils von oben auf die Felder hat, die fünfeckigen Figuren der Cohnheim'schen Felder als ein continuirliches Netz hervortreten, anstatt des beschriebenen 
viereckigen bei der Längsansicht. Solches, aus fünfeckigen Figuren zusammengesetzte Netz habe ich oft auf lange Strecken an einer Muskelfaser beobachten können.

Die feinen (mittelständigen) Fäden scheint schon Kölliker ${ }^{1}$ ) in der Muskelfaser des Axolotl gesehen zu haben. Er giebt jedoch keine Erklärung des Bildes und konnte auch natürlich bei seiner Auffassung von dem Bau der Muskelfaser den feinen Strichen nicht die Bedeutung beilegen, die aus meiner Darstellung hervorgeht.

Die Quej- und Längsfäden zwischen den dicken Muskelstäbchen sind schon von Heitzman ${ }^{2}$ ) beobachtet worden, der die Muskelfaser als ein aus protoplasmatischen Fäden bestehendes Netz auffasst.

Meine Darstellung der Structurverhältnisse, die ich, dem gegenwärtigen $Z$ wecke entsprechend, nur in groben Umrissen gegeben habe, beansprucht nicht, alle Contractionserscheinungen der quergestreiften Muskelfaser zu erklären; sie gewährt aber einen, wenn auch beschränkten Einblick in das Wachsthum der letzteren, sowie durch sie auch die Neubildnng von Muskelfasern verständlich wird.

Nac̉h Fertigstellung meines Manuscriptes kam mir eine kürzlich erschienene Arbeit von Retzius s') zu Händen, welche den Bau der quergestreiften Muskelfaser in sehr eingehender Weise behandelt. Da Retzius in seinen Untersuchungen zwar zu Bildern gelangte, welche ich der Hauptsache nach als zutreffend bestätigen kann, meine Auffassung dieser Bilder aber eine verschiedene ist, babe ich meine Präparate noch einmal sorgfältig geprüft, um eventuell meine Ansichten zu berichtigen. Das Resultat dieser abermaligen Prifung ist jedoch so ausgefallen, dass ich mich zur Aufrechterhaltung meiner Auffassung' von der Muskelstructur berechtigt glaube.

Eine erschöpfende Besprechung der Retrius'schen Arbeit passt nicht in den Rahmen dieses Aufsatzes. Nur in Kurzem will ich die übereinstimmenden (von meiner Seite bestätigenden) und die differirenden Punkte anführen.

Retzius betrachtet die Cobnheim'schen Felder, wie ich, nicht als die Querschnitte von Scheidewänden, die sich durch die

1) Gewebelehre 1867, p. 152. Fig. 103.

2) Wiener Sitzungsber. Bd. 1. XVII. Abth. 3. 1873.

3) Zur Kenntniss der quergestreiften Muskelfaser. Biolog. Untersuch. Jahrgang 1881. 
Länge der Muskelfaser erstrecken, sondern als ein in regelmässigen Abständen von einander stehendes Fadennetz, gebildet von den Zellenausläufern der Muskelkörperchen, Er beschreibt und zeichnet für die Längsansicht der Muskelfaser rectanguläre Fadennetze, deren Knotenpunkte Querkörnerreiben bilden. Es giebt Querkörnerreihen der 1., 2. und 3. Ordnung. Die der 1. Ordnung entsprechen der Krause-Amici'schen Linie, tiber die Locirung derjenigen der 2. Ordnung konnte ich keine Klarbeit gewinnen, die der dritten sind den Engel mann'sehen Nebenscheiben gleichzustellen. Die Körner (1. Ordnung) sind die optischen Durchschnitte der Fäden, welche die Coh nh ei m'schen Felder begrenzen.

Retzi us griundet seine Anschauungen auf vergoldete Muskelfasern von Dytiscus marginalis. Für den Frosch zeichnet er nur Körnerreihen der 1. Ordnung.

Um den Unterschied zwischen der Retzias'schen Ansicht und der meinigen zu präcisiren, adoptire ich den Ausảruck: „Körnerreihen" und würde mich nun so fassen:

Die Querkörnerreihen der 1. Ordnung entsprechen den dunkeln Querbändern, ihre Querverbindungsfäden den Hens en'schen Linien; die der 2. Ordnung fallen mit den Querstreifen in den hellen Querbändern zusammen (Krause-Amici'sche Linie). Diese Körnerreihen entsprechen, die ersteren einem gröberen, die letzteren einem feineren Querfadennetze. Der Länge nach betrachtet reihen sich die Körner der Querreihen 1. Ordnung . zu Längskörnerreihen 1. Ordnung aneinander. Dies sind die bekannten Längslinien der Muskelfaser. Alternirend mit diesen bemerkt man unter günstigen Umständen Längskörnerreihen der 2. Ordnung, welche den mittelständigen Punkten entsprechen. Die Körner der 1. Ordnung sind die Knotenpunkte der Cohnheim'schen Felder, die der 2. die Knotenpunkte eines feineren Netzes. In nicht geschrumpftem Zustande erscheinen die Körner als Stäbchen.

Auf Letzteres lege ich besonders Gewicht. Ich habe von Wirbelthieren Präparate erhalten, durch welche der directe Uebergang der Knötchen in Stäbchen beobachtet werden konnte und in welchen die Stäbchenreihen fast ebenso deutlich zu Tage traten, wie dies an Osmiumpräparaten geschieht. An anderen lösten sich die dunkeln Querbänder je nach der Focirung sowohl in Knötchen wie in Stäbchenreihen auf. Es ist hin und wieder behauptet worden, die Muskelstäbchen färben sich nicht mit Gold. Dies ist 
ein Irrthum, welcher sich aus Vorstehendem leicht erklärt. Man tubersah die Identität von Stäbchen und Körnern.

Uebrigens muss ich gestehen, dass ich bei Hydrophilus in der Längsansicht nie so schöne Netze mit Goldchlorid erhielt, wie Retzius dieselben für Dytiscus marginalis herstellte. Ueber die Structurverhältnisse bei Dytiscus, von denen Retzius bei seiner Deutung der Körnerreiben ausgeht, enthalte ich mich jeden Urtheils. Für die Wirbelthiere aber muss ich meine Angaben und Auffassungen aufrecht erhalten.

Die mittelständigen Punkte, die constante Gebilde sind und mir für die Erklärung der Muskelstructur von grosser Bedeutung zu sein scheinen, sind als gelegentliche Erscheinungen auch von Retzius beobachtet worden (p. 6).

„Zuweilen sieht man in den Zwischenräumen einen rothen Punkt, welcher als Durchschnitt eines einzelnen Fadens erscheint; solche einzelne Punkte oder Knötchen kommen besonders in der Umgebung der Enden der Zellkörper (?) vor.“

\section{Die postembryonale Neubildung der quergestreiften Muskelfaser.}

Untersucht man die mit Goldchlorid behandelten Muskeln junger oder auch älterer Mäuse, vorzugsweise im Frïhjahre, so findet man eine grosse Menge spindelförmiger Körper, die theilweise in Ketten zusammenhängen und den Muskelfasern parallel liegen. Sie sind mit letzteren in Zusammenhang und bilden bogenförmige Vorsprünge an dem Profil der Faser. Durch die Zerzupfung: erscheinen sie oft von einander getrennt und sie liegen, je nach der Intensität des mechanischen Eingriffs bei der Anfertigung: des Präparats, vereinzelt und mehr oder weniger regellos zwischen den Muskelfasern. Es sind dies jedenfalls die Gebilde, welche Margo') unter dem Namen "Sarcoplasten" beschrieb, und "die in den Zwischenräumen der schon fertigen Muskelfasern, also ausser-

1) Neue Unters. über die Entwicklung, das Wachsthum, die Neubildung und den feinern Bau der Muskelfasern. Wiener Sitzungsber. XXXVI S. 229 und 230 . 
halb des Sarcolemma liegen, und zwar theils isolirt, theils gruppenweise beisammen und in versehiedener Entwickelungsstufe, manche sogar im Begriff, zu einer Muskelfaser zusammenzuschmelzen." Die Beschreibung stimmt; Margo's Deutung dieser Bilder ist jedoch, wie ich zu beweisen gedenke, eine irrthümliche. Jene Spindeln mögen es auch wohl gewesen sein, welche von Wittich zu der Annahme verleiteten, dass sich Muskelfasern aus dem sie umgebenden Bindegewebe, dem Perimysium internum, entwickelten.

In Wirklichkeit sind diese Spindeln proliferirende, aus ihrem Zusammenhange gerissene Muskelkörperchen, wie aus Folgendem erhellen wird.

Man möge sich erinnern, wie bei der Beschreibung der Muskelfasern besonderes Gewicht darauf gelegt wurde, dass die Muskelkörperchen alle in parallel laufenden Linien liegen und dass ihre Protoplasmafortsätze unter Umständen ineinander übergehen (Fig. 1).

Wie nun bei pathologischen Processen die krankhaften Veränderungen zuerst in dem Protoplasma der Muskelkörperchen, also in jenen Fortsätzen auftreten; wie hier zunächst eine Vermehrung: des Protoplasma entsteht, welcher später eine degenerative Metamorphose folgt, so zeigen sich an eben diesen Stellen auch die vorbereitenden Veränderungen zur Neubildung von Muskelfasern, und zwar glaube ich beobachtet zu haben, dass die ersten Anfänge dieses Processes in der Näbe des Nervenendapparates zu Stande kommen.

An einer oder mehreren jener Muskelkörperchenreihen tritt um die Kerne herum ein Vermehrung des Protoplasma ein; auch die Kerne werden grösser, besonders länger; sie theilen sich in der Mitte, rücken auseinander und Protoplasma fuillt die Lücke. Durch fortgesetzte Theilung der Kerne und entsprechende Vermehrung des Protoplasma, wobei eine Einschnürung des letzteren zwischen je zwei Kernen stattfindet, wird eine Kette von Spindelzellen hergestellt, welche nunmehr den Raum zwischen den ursprünglichen Muskelkörperchen ausfüllt. Diese Wucherung der Muskelkörperchen ist auf Kosten der contractilen Substanz bis za einer gewissen Tiefe und Breite vor sich gegangen durch Einschmelzung derselben, und, wie ich glaube, Riickumwandlung derselben in Protoplasma. Es sieht nun so aus, als ob die Einschnürung des Protoplasma und die dadurch bedingte Spindelform der jungen Muskelkörperchen uur der vorbereitende Schritt 
zu einer völligen Lostrennung der einzelnen Körperchen von einander wäre. Dies geschieht aber nicht; im Gegentheil, die Vertiefungen an den Einschniurungsstellen werden mit Protoplasma ausgefüllt und statt einer Kette von zusammenhängenden Spindelzellen hat man nun einen soliden, ziemlich gleichmässig dicken Strang vor sich, bestehend aus einer homogenen Protoplasmamasse, in welcher in regelmässigen Abständen die Muskelkerne eingelagert sind (vgl. Fig. 4 und 5). Nun beginnt an der Peripherie des Protoplasmastranges die Differenzirung des contractilen Gewebes in der von Max Schultze für die Entwicklung der Muskelfaser im Embryo angegebenen Weise : "Unter Abnahme der Elementarkörnchen formt sich das contractile Protoplasma durch innere Veränderungen." Längs- und Querstreifen, d. h. die Netzbildung treten auf, die Kerne rücken immer weiter auseinander; die Faser wächst in die Länge. Die Kerne bleiben noch eine Zeit lang durch Protoplasmafäden untereinander verbunden.

Es fragt sich nun, wann die Lostrennung der neuen Muskelfaser von der Mutterfaser stattfindet.

Schon zu der Zeit, da die werdende Faser noch eine Kette von spindelförmigen Muskelkörperchen bildet, scheint eine Durchbrechung, resp. Einschmelzung des Sarcolemms der Mutterfaser vor sich zu gehen; man bemerkt wenigstens an der Spindelkette keine Contouren, die darauf hinweisen, dass dieselbe noch innerhalb des Sarcolemms der Mutterfaser liege. Erst später, mit der Differenzirung des contractilen Gewebes aus dem Protoplasma der Muskelkörperchen, zeigt sich ein schwacher Saum an den Umrissen der jungen Faser. Es ist also anzunehmen, dass das Sarcolemm der jungen, vorerst mit e iner Reihe von. Kernen versehenen Muskelfaser die Summe der Zellmembranen der Muskelkörperchen ist.

Alle diese Vorgänge finden unter dem Einflusse der Mutterfaser statt, mit welcher die Tochterfaser noch bis zu der Zeit, wo sie ihre eigenen Nerven erhält, in einem gewissen Zusammenhange bleibt. Die nengebildete Faser ist, so lange sie nicht eigens innervirt ist, auf die Mutterfaser fuir ihre Ernährung angewiesen. (Siehe weiter unten.)

Aus dieser Darstellung ist es erlaubt, folgende Schlisse zu ziehen:

a) dass es eine physiologische Neubildung von Muskelfasern im Thiere giebt;

b) dass die (junge) Muskelfaser nicht aequivalent 
einer Zelle ist, sondern dass sie die Summe einer Reih'e von Zellen darstellt, wobei die Kerne die Zellente rritorien markiren;

c) dass das Sarcolemm der (jungen, noch nicht innervirten) Muskelfaser ein Ausscheidungsproduct der Muskelzellen und structurlos ist.

Weiss mann $\mathbf{n}^{\mathbf{1}}$ ) scheint das spätere Stadium des oben beschriebenen Neubildungsprocesses der Muskelfaser gesehen zu haben. Er nennt es Randabspaltung und versteht darunter die Abspaltung eines kleinen Streifens der Muskelfaser. Seine Abbildungen zeigen alle schon vollständig differenzirte Fäden. Dabei sollen alle Fasern gleiche Länge haben und zwar die ganze Länge des Muskels.

Nach meinen Beobachtungen findet nun eine solche einfach mechanische Randabspaltung in dem Sinne We'issmann's nicht statt; der Vorgang ist ein complicirterel. Das Wesentliche an letzterem ist die Wucherang und Kettenbildung der Muskelkörperchen und die Constituirung der Spindelkette als individuelles Gebilde, trotz eines gewissen Zusammenhanges mit der Mutterfaser. Ob die Muskelkörperchenkette sich von Sehnenansatz zu Sehnenansatz erstreckt, konnte ich nicht eruiren. Auf Weissmann's vermeintliche Zweitheilung der Muskelfasern komme ich bei den Muskelspindeln des Frosches zu sprechen.

Margo's Sarcoplasten sind, wie schon oben angedentet, Muskelkörperchen, die aus dem Zusammenhange als Ketten gerissen sind. Daraus, dass diese Körperchen lose zwischen den Muskelfasern gefunden werden, während er sie andererseits zu Ketten angeordnet sah, folgerte Margo, dass die Körperchen als individuelle Gebilde mit einander verwüchsen. Wie die Anschaumg von der dachziegelartigen Anordnung zu Stande kam, kann ich mir nicht erklären.

Den meinigen ähnliche Bilder scheint $\mathrm{Kraske}^{2}$ ) (dessen Arbeit mir leider nicht zugänglich war) erhalten zu haben; er kommt aber zu dem Schluss, dass nach Abspaltung der Muskelzellen von der Substanz der Faser, die Zellen je zu einer jungen quergestreiften

1) 1. c.

2) Experimentelle Studien üb. d. Regeneration der quergestr. Muskeln. Habilitationsschr. Halle a. S. „Jahresberichte“ f. 1878. 
Muskelfaser auswachsen; eine Zusammenwachsen mehrerer Muskelzellen zu einer Muskelfaser findet nicht statt.

Es erübrigt noch, eine Theorie der Muskelfaserneubildung von Pere $\operatorname{mesch~o}^{1}$ ) zu erwähnen, welcher zu der Ansicht gelangt, dass ausser der Theilung in $W$ eissmann'schen Sinne, aus den Muskelkernen bei ausgewachsenen Thieren sich im Innern der alten Muskelfasern neue bilden. Er stïtzt diese Behauptung auf Bilder, wie sie dem in Fig. 3 entsprechen und die ich vorzugsweise bei der Eidechse beobachtete. Dieselben zeigen Kernsäulen im Innern von Muskelfasern, welche letztere von normaler Dicke sind. Ich bin betreffs dieser Kernsäulen za keinem definitiven Schlusse gekommen; doch bin ich geneigt, sie für den Ausdruck einer Modifikation von Muskelwachsthum zu halten, wobei dasselbe mehr in der Centralachse der Faser geschieht, als an der Peripherie.

Das weitere Wachstbum der Muskelfasern, sowie ibre Versorgung mit Nerven lehrt die Untersuchung der

\section{Muskelspindeln.}

Mit diesem Namen bezeichnete $K \ddot{u} \mathbf{h} n \mathrm{e}^{2}$ ) mehr oder minder spindelförmige, mit Nerven zusammenhängende Körper, die sich in den Muskeln gewisser Thiere vorfinden, über deren Bedeutung er jedoch im Zweifel war. Kühne fand diese Gebilde in den Muskeln der Ratte, später bei der Maus, Eidechse, Coluber natrix und dem Kaninchen und gab die erste genane Bescbreibung davon. K̈̈lliker hatte analoge Körper unter dem Namen "Nervenknäuel" für den Brusthautmuskel des Frosches beschrieben. Ich ziehe es vor, mit $K$ ühne den Namen ,Muskelspindel“ beizubehalten, da alle übrigen, wie „Nervenknäuel, „Muskelknospen“, „Nervenknospen" die Bedeutung in mehr oder weniger unrichtiger Weise präjudiziren.

Selbst bis auf den heutigen Tag sind die Muskelspindeln räthselhafte Gebilde geblieben und ihre Erklärung ist nie über die Hypothese hinausgegangen. Während Manche in ihnen Neubildung

1) Die Entwicklung der quergestreiften Muskelfaser aus Muskelkernen. Virckow's Archiv 1863 p. 116.

2) Die Muskelspindeln. Virchow's Archiv 1863 p. 528. 
Ueber die Muskelspindeln sowie Bemerkungen über Structur etc. 333

und Wachsthum von Muskelfasern und Nerven sahen, waren sie fiur Andere der Ausdruck regressiver Metamorphose. Kühne, wie schon erwähnt, enthält sich jeden Deatungsversuches. Köllike ${ }^{1}$ ) hält die "Nervenknäuel" oder "Nervenknospen" beim Frosche für Bündel junger Muskelfasern. Er beschreibt sie als bei Winterfröschen vorkommend, und auf den ersten Blick an Tastkörperchen oder Endkolben erinnernd. „Selbst bei genauerer Untersuchung erscheinen die fraglichen Gebilde als etwas verbreiterte Stellen schmalerer Muskelfasern, die durch einen grossen Reichthum an mehr rundlichen Kernen sich auszeichnen, za denen meist eine einzige seht breite Nervenfaser tritt, um sie mit einigen Windungen und knäuelförmigen Bildungen, in denen auch Theilungen vorkommen, zu umgeben und oft unzweifelhaft in dieselben einzutreten." Mittelst der Essigsäurebehandlung erkannte dann Kölliker, dass die vermeintliche einfache Muskelfaser aus einem ganzen Bundel von 3-7 feinen Fasern bestand, zwischen denen die Fasern nur hindurchtreten, und dass diese Körperchen es waren, aus welchen We ismann die Zweitheilung der Muskelfasern ableitete. Kölliker's Meinung ist, dass die Muskelspindeln Theilungs- und Wachsthumsvorgänge von Muskeln und Nerven darstellen und „dass die ursprünglichen blassen Nervenenden durch Wucherung und Kern. vermebrung sich so entwickeln, dass sie schliesslich alle neuen Fasern za versorgen im Stande sind."

Krause ${ }^{2}$ ) sieht in den Nuskelspindeln den Vorgang der Vermehrung von Muskelfasern. „Jene Vermehrung geschieht, indem die Nervenfaser der Endplatte wuchert, sie bildet Knäuel doppelt contourirter, aus Theilungen hervorgeganger Fasern."

Ranvier ${ }^{3}$ ) lässt es unentschieden, ob die Spindeln einen Wachsthums- oder Rückbildungsprocess bedeuten.

Gesehen, wenn auch in ihrer vollen Bedeutung nicht erkannt, wurden die in Frage stehenden Gebilde noch von anderen Beobachtern. So schildert Peremeschko ${ }^{4}$ ) den Process der Muskelfaserneubildung nach der Art Weismann's, dass sich alte Muskelfasern spalten und dass wir an der Stelle einer Faser ein ganzes

1) Handbuch d. Gewebelehre 1867 p. 173 und 174.

2) Allgemeine und mikroskop. Anat. 1879. p. 499.

3) Legons sur le système nerveux.

4) 1. c. 
Bündel haben. Seine Abbildungen entsprechen den Bildern Weismann's, d.h. den Muskelspindeln, wobei die dazugehörigen Nerven iibersehen wurden.

$\mathrm{Kraske}^{1}$ ) behauptet, „dass die sogen. bandförmigen Elemente, kernreichen Platten, Muskelknospen der Autoren, nicht Entwicklungsformen junger, sondern Theile alter Fasern sind."

In jüngster Zeit macht wieder $G \bullet \lg \mathrm{i}^{2}$ ) anscheinend als etwas Neues auf feine Muskelfaserbündel aufmerksam, „die die Merkmale embryonaler Fasern darbieten und nicht selten inmitten der gewöhnlichen Muskelbündel, oder häufiger noch in dem interfasciculären Bindegewebe vorkommen. Sie bestehen aus 5-6-8 Fasern etc." Von den zu den Muskelbündeln gehörigen Nerven wird nichts erwähnt; dennoch hatte man es hier unzweifelhaft wieder mit Muskelspindeln zu thun.

\section{Die Vereinigung von Muskelfasern und markhaltigen Nerven} (l. Ordnung).

In Folgendem will icb den Nachweis zu liefern versuchen, dass die Muskelspindeln junge Muskeln in dem Stadium ibrer Entwicklung darstellen, in welchem sie mit eigenen Nerven resp. Nervenendapparaten versorgt werden. Am besten lassen sich die dabei stattfindenden Vorgänge an der Muskelspindel der Eidechse verfolgen. An ihnen kann man Schritt für Schritt die Entwicklung: der Endplatte, sowie das Wachstbum der Muskelfaser studiren.

Nachdem die neue Muskelfaser auf die seiner Zeit beschriebene Weise zu Stande gekommen ist, scheint sie, obwohl deutlich als individuelle Faser erkennbar, noch längere Zeit mit der Mutterfaser in Zusammethang zu bleiben und von ihr in ihrer Ernährung abbängig zu sein. Sie hat nur eine, vermittelst Protoplasmafäden hergestellte und gewöhnlich in der Mitte der Faser liegende Kernreihe. Jetzt wächst nach uns unbekannten Gesetzen eine markhaltige Nervenfaser an die noch nicht innervirte Muskelfaser heran. Diese wachsende Nervenfaser unterscheidet

1) 1. c.

2) Contribuzioni all' istologia dei muscoli volontari. Nach einem Berichte Bizzozero's in Hofmann und Schwalbe's Jahresbericht für 1881. 
sich von den gewöhnlichen dadurch, dass alle Elemente an ibr in grösserem, man möchte sagen colossalem Maassstabe erscheinen. Nicht nur sind die Markmäntel ausserordentlich stark, sondern auch die Henle'sche Scheide mit ihren Kernen wird ungewöbnlich dick und lam ell är, nach Art der lamellären Bindegewebsscheiden der Nervenbündel. Die R anvier'schen Schnurringe erscheinen in verhältnissmässig kurzen Abständen und die dazwischen liegenden Nervensegmente haben oft das Aussehen ron riesigen Spindelzellen (Figg. 9 und 12). Der Nerv erscheint unter Umständen so dick wie die zu innervirende Muskelfaser. In der Regel besteht die Henle'sche Scheide aus zwei Lamellen.

Es können nun in dem Processe der Vereinigung von Nerv und Muskel zwei Fälle eintreten: entweder tritt der Nerv unter mehr oder weniger rechtem Winkel an die Muskelfaser heran (Figg. 11 und 13), oder er läuft vor der definitiven Vereinigung eine Strecke der letzteren parallel (Fig. 7). In beiden Fällen breitet sich die äussere Lamelle der Bindegewebsscheide des Nerven röhrenförmig über die Muskelfaser aus nnd umbüllt sie auf diese Weise auf eine beträchtliche Strecke, die innere, etwas dünnere Lamelle dagegen hält sich dicht an die Nervenfaser, begleitet sie als gewöhnliche Henle'sche Scheide und geht schliesslich in das Sarcolemm der Muskelfaser über, an deren Profil sie durch Kerne erkenntlich ist (Figg. $7 \mathrm{c}$ und $8 \mathrm{c}$ ).

Es bereiten sich nun eine Reihe höchst interessanter Veränderungen in der jungen Muskelfaser vor. Schon die oberflächlichste Beruhrung des Nerven mit der Muskelfaser ruft in dieser einen Wucherungsprocess der Kerne hervor; und zwar beginnt diese Wucherung stets an dem Kerne, welcher der Nervenspitze zunächst liegt (Figg. 7 a and 8a).

Der Kern vergrössert sich und umgiebt sich mit einem dicken Protoplasmamantel. Es erfolgt eine Quertheilung und Lostrennung der Theilstücke, wonach Protoplasma in die Lïcke zwischen die beiden Kerne einrückt. Durch fortgesetzte Wiederholung dieses Vorganges entsteht eine Kernsäule in ähnlicher Weise, wie wir dies bei dem Neubildungsprocess der Muskelfasern gesehen haben. Die contractile Substanz wird hierbei eingeschmolzen; sie verwandelt sich in ein formloses Protoplasma. Je weiter von der Eintrittsstelle entfernt, desto geringer sind noch die Veränderungen, die aber schliesslich doch sich durch die ganze Länge 
der Muskelfaser erstrecken. Am lebhaftesten aber gehen Einschmelzung und Kerntheilung am Nerveneintritt vor sich.

Besonders sind es hier die Kerne, die auffallend an Umfang. zunehmen und zwar auf Kosten des sie umgebenden Protoplasma (Fig. 16). Bald sind sie zu solchen Dimensionen angewachsen, dass sie sich gegeneinander abplatten und nun das Verhalten ihrer Längsachse zur Muskelfaser vollständig ändern. Lag früher ihre Längsachse derjenigen der Muskelfaser parallel, so liegt sie jetzt quer zu derselben. Dabei lässt sich eine oft frappante Abstufung in der Grösse der Kerne nach beiden Seiten von der Einmündungsstelle des Nerven wahrnehmen. Dieses Verhalten konnte ich am besten in den zusammengesetzten Spindeln der Maus beobachten (Fig. 25 und $25 \mathrm{~A}$ ). Schon $\mathrm{K}$ ü hne ${ }^{1}$ ) hat hier die Querstellung der Kerne gesehen und gezeichnet.

Jetzt hat also die theilweise umgesclumolzene Muskelfaser eine mehr oder weniger ausgesprochene Spindelform. In der Mitte der Spindel ist das Protoplasma zwischen den Kernen auf schmale Brïcken reducirt; nach beiden Seiten hin werden die Protoplasmaschichten zwischen den Kernen umfangreicher, bis sich allmählich eine Uebergangszone zwischem formlosem Protoplasma und differenzirtem Gewebe, und dann, noch weiter entfernt, ausschliesslich contractiles Gewebe mit den gewöhnlichen Muskelkörperchen in den ursprünglichen $d$ bständen einstellt (Fig. $25 \mathrm{~A}$ ).

Durch fortgesetzte Theilung der grossen Kerne kommt an der Eintrittstelle des Nerven eine regellose Kernanhäufung zu Stande. Die die Kerne umgebenden Protoplasmamassen oder Zellenleibel sind untereinander verschmolzen, so dass man das Ganze einem riesigen Myeloplaxen vergleichen könnte.

Diese Masse nun ist es, mit welcher der Nerv als nackter Axencylinder unter wiederholter Verzweigung zusammenwächst, resp. verschmilzt. Die Kerne werden bei diesem Vorgange umgangen. Die Protoplasmabrïcken dienen den Axencylinderzweigen als vorgezeichnete Bahnen ihręs Wachsthums. So kommt es zul den hakentörmigen, rankenden Terminalfasern in der Endplatte der Eidechse und der Maus. So werden ferner durch Zusammenwachsen zweier sich begegnender Endfasern die Maschen gebildet, in welchen später die Muskelkerne als Grundkerne (noyaux fondamentaux, Ranvier) erscheinen. Zuweilen wächst eine Terminal-

1) I. c. 
Ueber die Muskelspindeln sowie Bemerkungen über Structur etc. 337

faser quer über einen der runden Muskelkerne hinweg, der nunmehr als Geästkern erscheint. (In dem Stadium der Verschmelzung ist es unmöglich, den Axencylinder von dem Protoplasma der Muskelkörperchen zu unterscheiden; ert später, wenn die Differenzirung. der contractilen Substanz eingetreten und das formlose Protoplasma vermindert ist, werden die Axencylinderfortsätze in der Gestalt der Endplatte sichtbar.)

Während der Nerv sich so mit der Muskelfaser in Verbindung setzt, schreiten Kerntheilung und Einschmelzung der contractilen Substanz stetig ron der Eintrittsstelle des Nerven nach beiden Seiten hin vor, und Goldpräparate weisen nun einen dunkeln Strang auf, welcher in gewissen Abständen mit hellen, ungefärbten Kernen durchsetzt ist.

Aus dieser Masse differenzirt sich dann aufs Neue unter fortgesetztem Sichtheilen und Auseinanderriicken der Kerne die contractile Substanz; die Faser wächst in die Länge und Dicke. Noch eine Zeitlang bleiben die Muskelkörperchen durch ihre Protoplasmafortsätze in der Richtung ibrer Längsachsen untereinander verbunden bis sich auch dieser Rest formlosen Protoplasmas in contractiles Gewebe umwandelt und man nun die ausgewachsene, resp. alte Muskelfaser vor sich hat. Unter pathologisehen Bedingungen oder zum Zwecke physiologischer Neubildung von Muskelfasern können sich die Kerne wieder mit Protoplasma umgeben und untereinander in der öfters erwähnten Weise in Verbindung treten.

Die Kerne aber am Eintritt des Nerven bleiben ohne regelmässige Form und Anordnung zwischen den Verästelungen des letzteren; resp. in den Maschen der Terminalfasern als Grundkerne liegen.

Die Endplatte kommt also im Prinzip dadureh zu Stande, dass der Terminalaxencylinder eines markhaltigen Nerven unter mancherlei Verästelungen mit dem Protoplasma (den Zellenleibern) von dicht nebeneinander liegenden Muskelkörperchen verwächst.

Kühne bezweifelt das Vorkommen der Geästkerne, welche von Cohnheim und dann wieder von Ranvier angenommen

1) Ueber die Endigung der motorischen Nerven in den quergestreiften Muskeln. Pflüger's Archiv Bd. XII. 
wurden. Ewald ${ }^{1}$ hat sie, andeutungsweise, in atrophirtem $\mathrm{Zn}$ stande gesehen. Nach eingehender Untersuchung dieses Punktes bin ich, angesichts der ausserordentlichen Seltenheit, mit welcher die fraglichen Kerne auftreten, zu der Ansicht gekommen, dass es sich hier möglicher Weise um Kerne der markhaltigen, extramuskulären Segmente handelt, die in Flächenansichten manchmal sehr schwer von den intramuskulären, sehr dicken Terminialfasern unterschieden werden können.

Die Scheidenkerne (noyaux vaginanx, Ranvier) sind die persistirenden Kerne der Henle'schen Scheide. Die übrigen Kerne beider Lamellen der Muskelspindel verschwinden später. Auch die Lamellen verschmelzen derart mit dem Sarcolemm, dass sie als individuelle Gebilde nicht mehr erkennbar sind; das Sarcolemm erscheint wieder kernlos, als einschichtige, hyaline Membran. Nur selten erhalten sich einige von jenen Kernen, die später noch demonstrirbar sind.

Die protoplasmatische Zone oder Plattensohle, die zu so vielen Conjecturen bezüglich der motorischen Wirkung des Nerven auf die Muskelfaser Veranlassung gegeben hat, ist lediglich jene Protoplasmamasse, in welcher die Muskelkerne eingebettet liegen und die sich nicht, wie das Protoplasma der übrigen Muskelkörperchen dies thut, in contractiles Gewebe differenzirt hat.

Je jünger die Muskelfaser mit ihrer Endplatte ist, desto mächtiger ist die Protoplasmaschicht, die sich, da sie die Kerne von allen Seiten umhüllt, bis zn einer gewissen Tiefe in die Muskelfaser erstreckt. So erklären sich die Beobachtungen Kühne's und Krause's, welche die Protoplasmamasse als Sohle beschreiben. Mit zunehmendem Alter reducirt sich das Protoplasma zu einer dünnen Schicht, in welcher Kerne und Terminialfasern in einer Ebene liegen, und verdient eher der den Namen einer protoplasmatischen Zone, den Ranvier vorgeschlagen hat, als den einer Plattensohle.

In jüngeren, protoplasmatischen Altersstadien ist es an Goldpräparaten oft unmöglich, die dicken Terminalfasern von den als dunkle, die hellen Kerne umgebenden Ringe erscheinenden Protoplasmabrücken zu unterscheiden (Fig. 17). In diesen Stadien ist es ferner, in welchen man dis Fortsätze des Protoplasmas der Endplatte beobachten kann, welche Gerlach zu der Annahme seines intravaginalen Nervennetzes veranlassten. Diese Protoplasmafort- 
Ueber die Mraskelspindeln sowie Bemerkungen über Structur etc. 339

sätze sind eben jene Zwischensubstanzlinien, in welche sich die Terminialfasern nach Gerlach fortsetzen ${ }^{1}$ ) sollen.

In Obigem habe ich die Grundziige, gewissermassen den Plan beschrieben, nach welchem sich die Vereinigung von Nerv und Muskelfaser bei der Eidechse vollzieht. Es mögen nun noch einige Modificationen und Details folgen, die dabei zur Beobachtung kommen.

Es giebt Muskelspindeln, zu denen zwei markhaltige Nerven treten (Fig. 12), wie es denn in der That Muskelfasern mit zwei Endplatten giebt. Für den Frosch hatte $K \ddot{\mathrm{u} h} \mathbf{n}$ e diese Behauptung gegen Krause aufgestellt. Bei der Eidechse habe ich zwei Endplatten an einer Muskelfaser beobachtet ${ }^{2}$ ).

Es kommen ferner Faille vor, in welchem ein Nerv an einer Einschnürungsstelle an die Muskelfaser herantrittt (Fig. 8). Aus der Einschnürung wächst eine Nervenfaser an den Muskelfaden heran und bildet die Endplatte. An fertigen Gebilden hat man nun den Eindruck, als ob zwei Nerven sich zur Bildung einer Endplatte vereinigten, während dies in der That nur von einem Nerven geschieht, der sich dann aus der Endplatte heraus weiter fortsetzt ${ }^{3}$ ).

Manchmal liegen die Muskelkörperchen der noch nicht innervirten jungen Muskelfaser nicht, wie dies gewöhnlich der Fall ist, in der Mitte derselben, sondern an der Oberfläche, unter Umständen an der entgegengesetzten Seite der herantretenden Nervenspitze (Figg. 7 und 8).

Oft fallen Zacken und Ausbuchtungen auf, welche sich an denjenigen Theilen der Spindeln zeigen, welche den höchsten Grad der Einschmelzung des contractilen Gewebes erreicht haben. Diese Bilder kommen durch Schrunpfung des Muskelfaserinhaltes, welche dureh die Säurebehandlung bewirkt wird, zu Stande.

1) Vgl. meine Arbeit "Ueber die Endigungen der markhaltigen und marklosen Nerven etc." Dieses Archiv Bd. XXI Taf. VIII Fig. 23.

2) 1. c. p. 178.

3) Ebendaselbst Taf. VIII Fig. 24. 


\section{Die Vereinigung von Muskelfasern mit marklosen und dünnen markhaltigen Nerveu (II. Ordnung).}

Eine auffällige Erscheinung bieten die Endigungen markloser oder dünner markhaltiger Nerven (II. Ordnung) dar, welche man in wechselnder Entfernung vor dem Eintritt des dicken markhaltigen Nerven (I. Ordnung) an derselben Muskelfaser beobachten kann. Es sind dies in ibrem fertigen Zustande dieselben Endigungen, welche ich ') als doldenförmige beschrieben habe, und die schon früher von Tschiriew ${ }^{2}$ ) gesehen und als embryonale Endplatten aufgefasst wurden. Diese Verbindungen von marklosen, resp. dünnen markhaltigen Nerven mit den Muskelspindeln der Eidechse habe ich so häufig gesehen, dass ich mich berechtigt glaube, sie als constante Vorkommnisse hinzustellen und den Satz auszusprechen, dass einejede Muskelfaser mit mindestenszwei nervösen Endapparaten versehen is $t$, deren einer von einem starken markhaltigen und der andere von dünnen markhaltigen oder marklosen Nerven gebildet wird. Die Muskelfaser der Eidechse speciell ist also mindestens mit einer Endplatte und einer Enddolde versehen.

In der Vereinigungsweise der beiden Nervenarten mit ihren Muskelnfasern lässt sich nun ein wesentlicher und höchst characteristischer Unterschjed constatiren. Wäbrend nämlich der Verwachsungsprocess der starken markhaltigen Nerven stets von einer ausgesprochenen Kernwucherung, kurz von sehr markirten Wachsthumsvorgängen begleitet ist; während hier die auffallendsten Structurveränderungen in gewissermassen stürmischer Weise sich vollziehen, und man fast den Eindruck erhält, als handle es sich um einen acut verlaufenden pathologischen Vorgang, bewerkstelligt sich die Vereinigung des dïnnen markhaltigen oder marklosen Nerven eine Strecke davon unter geringfügigen Veränderungen. Dort die grösste Thätigkeit aller Elemente, Kernwucherung, Einschmelzung von Geweben, Neubildung von kernreichen Membranen, anscheinend ein verschwenderischer Aufwand von Material und Kraft; hier die grösste Einfachheit und keine nennenswerthen Structurveränderungen. Entweder findet man die Enddolden schon gebildet,

1) 1. c. 178 .

2) Sur les terminaisons nerveuses dans les muscles striés. Arch. de Phys. norm. et patholog. 2. Série t. VI. 
Ueber die Muskelspindeln sowie Bemerkungen über Structur etc. 341

fix und fertig vor (Figg. 10e und 11d), während am anderen Nerveneintritt noch Alles in Vorbereitung und im Werden begriffen ist, oder man sieht, wie sich an einem oder zwei benachbarten Kernen ein kleiner Protoplasmahof gebildet hat, vermittelst dessen sich der Nerv mit der Muskelfaser in Verbindung setzt. (Vgl. Fig. 15a. Hier ist allerdings etwas reichlicher Protoplasma vorhanden, als dies gewöhnlich der Fall ist.) Eine Einschmelzung von contractilem Gewebe kommt hier gar nicht oder in nur geringem Grade zur Beobachtung. Dieselbe schreitet, wie schon erwähnt, von dem Eintritt des starken markhaltigen Nerven nach beiden Seiten hin gleichmässig vor.

Hieraus lässt sich schliessen, was man experimentell-physiologisch schon wusste, dass der dicke, als motorisch bekannte Nerv auch trophische Eigenschaften besitzt; dass die Wachsthumsbedingungen der Muskelfaser von diesem Nerven ausgehen. Es ergiebt sich aber ferner, dass dem dünnen markhaltigen oder marklosen Nerven trophische Eigenschaften nicht, oder nur in geringerem Maasse zukommen.

Bemerkenswerth ist der Umstand, dass schon die beginnende Verbindung, gewissermassen nur die Berührung des heranwachsenden dicken (trophischen) Nerven geniigt, um in den nächst gelegenen Muskelkörperchen den Anstoss zu der Reihe von Wachsthumsveränderungen zugeben. Man könnte versucht werden, bei solchen Bildern an die mysteriösen Vorgänge bei der Zeugung zu denken, bei welcher ja auch ein von Aussen herantretender Keim in dem Ei jene wunderbaren Veränderungen hervorruft, die zur Entstehung des nenen Individuums nothwendig sind. Auch in der jungen, mit der Mutterfaser noch zusammenhängenden Muskelfaser bedarf es erst des belebenden Einflusses eines eigenen Nerven, um ihr Wachsthum, ihre Ernährung und Function als einer individuellen Faser zu veranlassen.

Auffällig sind diejenigen Bilder, in welchen das Muskelkörperchen, an dem sich die ersten Wachsthamsveränderungen zeigen an der entgegengesetzten Stelle von dem Anheftungspunkte des Nerven liegt, wobei eine Schicht vollständig erhaltenen Gewebes zwischen Nervenspitze und Muskelkörperchen erhalten bleibt.

Was bedeuten nun die Enddolden? - Ts ch i r i ew's $\left.{ }^{1}\right)$ Ansicht,

1) l. c. 
welcher sie(terminaisons en grappe) als embryonale Endplatten ansah, kann ich nicht beipflichten, wie ich ferner, auf obige histo-genetische Beobachtungen gestützt, seiner Angabe widersprechen muss, dass sie nicht zusammen mit Endplatten an einer Muskelfaser vorkommen. Gerade ihr constantes Auftreten mit den motorischen Endplatten an einer und derselben Muskelfaser lässt mich annehmen, dass sie eine besondere Function zu erfüllen haben, dass sie die Endapparate der sensiblen Nerven an den Muskelfasern sind.

Die Frage, ob die quergestreiften Muskeln überhaupt sensible Nerven haben, kann man getrost bejahen. Experimentell und empirisch steht ja die Thatsache längst fest. Zwar ist der Muskel bei weitem nicht so empfindlich wie die Haut mit ihren zahlreichen und ausgebildeten sensiblen Organen; wir wissen aber zu gleicher Zeit, dass es einen von den Nerven der Haut unabhängigen Muskelsinn giebt und dass man Fälle beobachtet, in welchen das Muskelgefibl vollständig erhalten, während die Empfindlichkeit der Haut erloschen ist. Auch die muskulären Hyperalgien und Hyperästhesien, sowie das alterirte Muskelgefühl bei der atactischen Tabes dorsalis könnten hier angeführt werden. Wir wissen ferner, dass die dünnen markhaltigen Nerven und die daraus entspringenden marklosen Muskelnerven vorwiegend sensible sind; im Verlaufe obiger Darstellung aber habe ich den Nachweis geliefert, dass eine jede Muskelfaser ausser einem Endapparate von dicken (motorischen) Nerven auch kleinere Endapparate der feineren markhaltigen, resp. marklosen Nerven erhält.

Letztere sind also mit der grössten Wahrscheinlichkeit sensible Endapparate. Ihre Kleinheit verglichen mit den motorisch-trophischen Endplatten erklärt ihre physiologische Untergeordnetheit diesen Apparaten gegenüber.

Ein Befund, der mir öfters zur Beobachtung kam, scheint allerdings gegen die eben aufgestellte Behauptung: zu sprechen. Man trifft nämlich zuweilen auf Bilder (wie die in Fig. 16 dargestellten), in denen ein markloser Nerv, welcher aus einer motorischen Endplatte hervorgeht, in derselben Weise, wie dies für di marklosen Nerven als Regel beschrieben wurde, einen Endapparat an einer Muskelspindel zu bilden im Begriffe steht. Wenn man aber bedenkt, dass in die von markhaltigen Fasern gebildeten Endplatten auch marklose Fasern eintreten können, wie ich frither 
Ueber die Mtuskelspindeln sowie Bemerkungen über Strnctur etc. 343

nachgewiesen habe, so würe es ja denkbar, dass jene aus den Endplatten kommende Faser die Fortsetzung der in die Endplatte eintretenden wäre.

Für die Enddolden der Eidechse habe ich es ferner als characteristisch hingestellt ${ }^{1}$ ), dass sehr häufig zwei marklose Fäden in dieselben eintreten, d. h. dass aus einer Enddolde eine marklose Faser weiter geht, um an derselben oder einer benachbarten Muskelfaser in ähnlicher Weise zu enden. Obwohl dies vorzugsweise von der Zunge gilt, habe ich es doch auch in den Skeletmuskeln beobachtet. Bei der Untersuchung der Muskelspindeln war es mir nun zwar möglich, die Eigenthümlichkeit zu erklären (p. 339), wie sich ein markhaltiger Nerv aus einer Endplatte heraus entwickelt, um an einem anderen Orte wieder eine Endplatte zu bilden; das weit häufigere Vorkommen dieses Verhältnisses bei marklosen Nerven mit ihren Endapparaten war ich nicht in der Lage an den Muskelspindeln zu beobachten, was natürlich bei der Schwierigkeit, iiberhaupt passende Präparate zu bekommen, noch nichts beweist.

Die Muskelspindeln geben anch Gelegenheit die

\section{Neubildung and das Wachsthum markhaltiger Nerven im quergestreiften Muskel}

zu beobachten. Wie die postembryonale Neubildung der Muskelfasern in gewissen Details von der embryonalen abweicht, so auch die Neubildung von markhaltigen Nerven im Muskel des wachsenden Thieres von der im Embryo und in der Larve; gesetzt nämlich, dass die diesbeziiglichen herrschenden Angaben und Anschauungen richtig sind, woriber ich mir kein Urtheil erlauben will ${ }^{5}$ ).

Die Neubildung findet nun nicht so statt, dass sich marklose Fäden entwickeln, die sich etwa später erst mit einem Markmantel umgeben, sondern der Markmantel, und zwar ein auffallend massenhafter, bildet sich in gleichem Schritt mit den Ranvier'schen Schnüringen. Der Vorgang dabei ist ein sehr einfacher (Fig. 14).

Ueber den letzten Schniirring eines wachsenden markhaltigen

1) 1. c. p. 178 .

2) Ebendaselbst.

3) Vgl. Kölliker, Entwicklungsgesch. 1879. p. 601. 
Nerven hinaus sieht man einen speerförmigen Ausläufer ragen, das jüngste Nervensegment. Zum Unterschied von den vollständig. gebildeten Stabzellen '), die durch Gold intensiv dunkel gefürbt sind, erscheint diese letztere viel bläisser oder gar nicht gefärbt. Dieses speerförmige Ende des Nerven ist eine Zelle mit einem meistens mehr nach dem dickeren, hinteren Ende zu liegenden Kerne. An glïcklich gefallenen Präparaten kann man diesen Kern im Begriffe stehend, eine Theilung einzugehen, beobachten. Er ist länglich, liegt in der Längsaxe der Nervenfaser und die Theilung erfolgt in querer Richtung zur Längsaxe. An dem, der 'Theilungsstelle entsprechenden Puncte der Oberfläche der Zelle erfolgt eine Einbuchtung, die Andeutung des künftigen Schnürringes. Nach Theilung des Kernes entstehen zwei junge Stabzellen. Die Kerne rücken mehr und mehr auseinander unter stetigem Wachsthum der Stabzellen; die Marksubstanz, der Axencylinder und das Neurilemm differenziren sich aus dem Zellprotoplasma, der Schnürring accentuirt sich, der Kern, nach geschehener Differenzirung, rückt als "Kern der Schwann'schen Scheide" an die Oberfläche der Stabzelle.

Aus dieser Darstellung, welche ich hier nur anhangweise und skizzenhaft gegeben habe, ergiebt sich die Richtigkeit der Ranvier'schen Auffassung, wonach die abgeschnürten Nervenstiucke „Zellenterritorien" sind; es ergiebt sich ferner daraus, dass die sog. Kerne der Schwann'schen Scheide ebensowenig dieser Membran angebören als die oberflächlich gelegenen Muskelkerne dem Sarcolemm zukommen. Die Schwann'sche Scheide ist also histogenetisch ebenso als Zellmembran aufzufassen wie das Sarcolemm. Ihr Kern ist ein Nervenkern und mit seinem ihn umgebendem Protoplasmahofe bildet sich eine Nervenzelle, die histologisch dem Muskelkörperchen gleichwerthig ist.

So wird es erklärlich, dass die Schwann'sche Scheide als solche verschwindet, sobald sich der Nerv in die Nervenendplatte auflöst. Sie ist eben blos eine Zellmembran und bei der Theilung und Verschmelzung der marklosen Terminalfasern kommt es eben nicht zur Bildung eines Neurilemms, weil dasselbe hier zweck-

1) Diesen Ausdruck schlägt Frey in seinem Handbuche der Histologié 1876 p. 332 für die zwischen je zwei Schnürringen gelegenen Nervenabschnitte vor und ich will ihn hier aus Ermangelung eines bessern adoptiren. 
Ueber die Muskelspindeln sowie Bemerkungen über Structur etc. 345

los sein würde. Keineswegs also darf man annehmen, dass die Schwann'sche Scheide, wie dies bei der Henle'schen der Fall ist, auf das Sarcolemm sich fortsetzt.

Mit dem Wachsthum der Nervenfaser an sich hält dasjenige der Henle'schen Scheide gleichen Schritt, und dieses Wachsen vollzieht sich unter dem Schutze einer provisorischen Umhüllung, die für diesen Zweck von der äusseren Lamelle der Henle'schen Scheide gebildet, Nerv und Muskelfaser umgiebt. Das Perimysium internum hat also mit der Bildung dieser Scheiden nichts zu thun.

\section{Die Yuskelspindeln des Frosches.}

Bekannter als die Muskelspindeln der Eidechse, die ich als einfache bezeichnen möchte, sind die des Frosches, welche, da sie immer aus mehreren Nerven und Muskelfasern bestehen, z u s a m mengesetzte genannt werden mögen. Sie sind vielfach beobachtet und studirt worden und haben zu mancherlei Vermuthungen und zu unrichtigen Vorstellungen uiber Neubildung und Degeneration der quergestreiften Muskelfaser geführt. Ibren morphologischen Eigenschaften nach sind sie ziemlich genau bekannt, über ihr Wesen und ilure Bedentung war man sich nicht klar. Kölliker ${ }^{1}$ ) giebt in seinem Handbuche eine Abbildung, welche in Bezug auf Naturtreue den Kühne'schen Bildern allerdings bedeutend nachsteht, die aber andererseits die richtige Auffassung veranschaulichen soll, dass die Spindel in Wahrheit den Vereinigungsprozess von Nerv und Muskelfaser darstelle.

Die Abbildung, welche Ranvier ${ }^{2}$ ) giebt, entspricht ungefähr den Bildern Kühne's. Der Zusammenhang zwischen Nerven und Muskelfasern tritt nicht so deutlich hervor wie bei Kölliker.

Vergoldete Muskelspindeln des Frosches zeigen folgendes Aussehen: Ein starker markhaltiger Nerv, oft von 4- bis 5fachem Durchmesser der gewöhnlichen Nerven derselben Kategorie, mit lamellärer Scheide versehen, oder ein Nervenstrang, bestehend aus 2 oder 3 Nerven, tritt an die Spindel heran (Figg. 18 und 19). Die äussere Lamelle umgiebt die Spindel in röhrenförmiger Ausbreitung. Die Nerven theilen sich innerbalb dieser Einhüllang in

1) 1. c. p. 174 .

2) 1 . $\mathrm{c}$. 
der bekannten Weise und erscheinen gegen ihr Ende zu als Fäden, die mit dicken, kolbigen und kugeligen Anschwellungen besetzt sind. Diese Bildungen kommen durch die Gold-Säurewirkung zu Stande; das Myelin ist frisch gebildet und eine Schwann'sche Scheide für die Stabzelle hat sich entweder noch gar nicht oder nur ungenügend ausgebildet, um bedeutendere Contourveränderungen zu verhindern. Der sonstige Inhalt der Spindel präsentirt sich dicht an der Nerveneintrittsstelle als eine grob granulirte, von Kernen verschiedener Grösse und verschiedenem Brechungsvermögen durchsetzte Masse. Weiter von der Eintrittsstelle des Nerven entfernt verschwindet dieses wirre Durcheinander, es zeigt sich das gewöhnliche contractile Muskelgewebe, in welchem man noch schwärzliche oder rothbraune Flecken, d. h. kleine Parthien eingeschmolzener. Muskelsubstanz gewahrt.

Die umhüllende Membran, welche an den über dem Provil der Spindel erscheinenden Kernen auf eine geraume Strecke erkennbar ist, hört oft an einer Stelle auf, die deutlich durch das plötzliche Auseinanderweichen von Muskelfäden mit intacter Querstreifung markirt wird. Hier zeigen sich nun 4, 5 bis 10 Primitivbündel, jedes mit einer in der Axe der Muskelfaser gelegenen Kernreihe. Es hat den Anschein, als ob sich hier eine Faser in viele kleinere Fasern spaltet und als ob dieser Theilungsprocess innerhalb jener grob granulirten Masse vor sich gehe. In Wahrheit existirt jedoch die 'Trennung der Fasern durch die ganze Spindel hindurch und es ist die gemeinsame Umhïllung:smembran der zutretenden Nerven, welche eine grössere oder kleinere Anzahl invidueller, junger Muskelfasern zum Zwecke der Innervation zusammengefasst hat. Es spaltet sich also in der Spindel nicht etwa eine Mutterfaser in mebrere Tochterfasern, sondern das Aus. einanderweichen einer Anzahl von Fasern findet statt, weil sie durch die gemeinsame Umbüllungsmembran nur auf eine gewisse Strecke zusammengehalten werden. Die Thatsache, dass die Muskelfasern von vornherein als Einzelfasern in der Spindel lagern, lässt sich an jüngeren Muskelspindeln demonstriren, in welchen die Veränderungen, wie ich sie für die Einzelspindeln der Eidechse beschrieben habe, noch nicht in besonders grossem Umfange Platz gegriffen haben. Man kann hier beobachten, dass sich die Anfänge desselben Processes: Kerntheilung, Einschmelzung des contractilen Gewebes und Zusammenwachsen des Nerven mit der Muskelfaser 
Ueber die Muskelspindeln sowie Bemerkungen über Structur etc. 347

in ähnlicher Weise vollziehen, wie bei der Eidechse. An der Einzelspindel der letzteren hat man ein Paradigma fiur die Vorgänge in der zusammengesetzten Spindel des Frosches.

Wegen der vielen, ïbereinander liegenden Muskelfasern und ihrer dunklen Protoplasmamassen, sowie wegen der Masse wuchernder markhaltiger Nerven ist es unmöglich, die einzelnen Stadien des Muskelwachsthums und der Vereinigung von Muskelfaser und Nerv zu beobachten. Erst nachdem die provisorische, gemeinsame Umbüllungsmembran geschwunden ist und die einzelnen Muskelfasern frei geworden sind, erhält man an jungen Muskelfasern eine Einsicht in die Bildung der für den Froseh characteristischen Nervenendapparate (Fig. 20).

Statt der massenbaften Kernansammlung mit den Zwischenschichten von Protoplasma, in welcher sich die Terminalfasern bei der Eidechse vertheilen, sind es hier die durch ihre massigen Fortsätze unter einander in der Längsaxe verbundenen Muskelkörperchen, mit deren Zellenleibern die dicken Endfasern nach vorangegangener Gabelung verwachsen. In den jungen, eben erst innervirten Muskelfasern erscheinen die Endfasern des typischen Endbüschels als dicke, dunkle Stränge, an denen man nicht unterscheiden kann, was Nerv und was Protoplasmafortsatz ist. Mit zunehmendem Alter werden auch hier die Nervenfasern dünner und die Protoplasmafortsätze schwinden. Die Külnne'schen Besatzkörperchen sind als also Muskelkerne, d. h. Kerne von Muskelkörperchen, dessen Protoplasma sich bis auf winzige Ueberreste zu contractilem Gewebe umgewandelt hat. Sie sind in der Regel grösser als die gewöhnlichen Muskelkerne, weil sie an dem Ernährungscentrum liegen.

$\mathrm{K} \ddot{u} \mathrm{~h}$ ne gelang es durch verlängerte Einwirkung sehr verdünnter Salzsäure die quergestreifte Substanz der Muskelfasern zum Schwinden zu bringen, so dass nur der Sarcolemmschlauch mit der frei darin flottirenden Nervenendigung übrig blieb. Die Besatzkörperchen blieben bierbei an den Endfasern baften. Hieraus zog K $\mathrm{u} h \mathrm{he}$ den Schluss, dass die ersteren nichts mit den Muskelkernen zu thun haben. Auch mir sind solche Bilder bekannt an Präparaten, welche ich durch verlängerte Ameisensäurewirkung erhielt; doch konnte ich an ihnen sehr häufig den anhaftenden Protoplasmastrang nachweisen, in welchem die Kerne eingebettet lagen. Durch die Reste von Muskelkörperchenprotoplasma bleiben 
also die „Besatzkörperchen" mit der Nervenendfaser im Zusammenhange. Ausserdem kann man durch verschiedene Einstellungen mit der Micrometerschraube nachweisen, dass die Kerne unter, nie über, höchstens manchmal durch Druck und Verschiebung. neben den Terminalfasern liegen.

Man könnte aber fragen, wie es denn komme, dass es Terminalfasern giebt, die nicht mit Besatzkörperchen versehen sind, also nicht mit Muskelfasern in Verbindung stehen? Für die Erklärung dieser Thatsache muss ich wieder auf die Betrachtung des Jugendzustandes der Muskelfaser zurückweisen, in welchem die Muskelkörperchen durch Protoplasmafortsätze untereinander verbunden sind. Es genügt, dass sich der Nerv mit einem solchen Protoplasmafortsatz in Verbindung setzt. Beim späteren Wachsthum geht der Zusammenhang mit den Muskelkörperchen verloren durch Umwandlung des Protoplasmas in contractile Substanz.

Es giebt aber im typischen Nervenendbisschel des Frosches noch eine andere Art Kerne der Terminalfasern, die man gewöhnlich an den Theilungsstellen der letzteren antrifft und meist eine dreieckige Gestalt zeigen (Fig. 22 a a). Sie liegen in einer Ebene mit den Nervenfasern und wahrscheinlich ausserhalb des Sarcolemms. Ich halte sie für Kerne der Schwann'schen Scheide, also für Nervenkerne. Sie sind jenen Kernen gleichwerthig, die man häufig an Bifurcationen markloser Fasern zwischen den Muskelfasern antrifft.

Grundkerne, welche histogenetisch auch nur Muskelkerne, jedoch von veränderter, meist rundlicher Gestalt oder in veränderter Längsaxenlage sind, kommen zwar im typischen Endbüschel nicht so häufig vor wie in der Endplatte, doch fehlen sie nicht absolut und markiren oft, wie in der Endplatte der Eidechse, Umbiegungsund Theilungsstellen der intramuskulären Nervenendfasern (Fig. $22 \mathrm{e} e$ ).

Ausser den typischen Endbüscheln kommen auch Endapparate beim Frosch vor, welche sich der Form der Endplatte nähern ${ }^{1}$ ). Dieselben kommen in ähnlicher Weise wie bei der Eidechse zu Stande, indem sich an der Eintrittsstelle des Nerven eine grössere Kernanhäufung, also eine ausnahmsweise regere Muskelkörperchenwucherung einstellt, in deren Protoplasma-

1) Vgl. dieses Archiv XXI. Bd. Taf. VII Fig. 2. 
Ueber die Muskelspindeln sowie Bemerkungen über Structur etc. 349

schichten die Endfasern der Nerven in den verschiedensten Richtungen verlaufen. Bei der Endplatte sind also die für die Verbinlung mit den Nerven bestimmten Muskelkörperchen dichter zusammengedrängt, bei dem Endbüschel liegen sie weiter auseinander. Daher die protoplasmatische Zone bei jener, die bei diesem fehlt, wenigstens bei alten Muskelfasern. Je älter die letzteren, desto mehr verschwindet die Zone. Ich möehte jedoch darauf aufmerksam machen, dass der grössere oder geringere Umfang der Protoplasmazone auch durch eine mehr oder minder rege Muskelthätigkeit des Thieres und den dadurch bedingten Stoffumsatz beeinflusst sein könnte.

Auch an den Muskelspindeln des Frosches trifft man, wenn man dieselben lang genug erhält, immer markhaltige Nerven der II. Ordnung und marklose Nerven, die sich mit den in der Spindel gelagerten Muskelfasern ohne nennenswerthe Veränderungen in ihnen hervorzurufen, in Verbindung setzen (Fig. 18a). In dieser Figur erscheint der Nerv auffallend dick für einen Nerven der II. Ordnung; doch wird dies weniger befremdend erscheinen, wenn man bedenkt, dass alle wachsenden Nerven viel grössere Dickendurchmesser haben, als die ausgewachsenen.

An den Endigungen markloser Nerven jüngerer Muskelfasern lässt sich das Verhältniss zwischen Terminalfaser und Muskelkörperchen noch klarer demonstriren als an den gewöhnlichen musculären Endapparaten (Fig. 23). An Proflbildern kann man den Unterschied zwischen Geästkernen und Besatzkörperchen darthun (Fig. 24). In Bezug auf die ersteren wlirde es bei der Flächenansicht unmöglich sein, ihre intra- oder extranuskuläre Lage zu bestimmen. Aber auch bei solchen Profilbildern, in welchen die Nervenkerne dicht der Muskelfaser aufgelagert erscheinen, kann man oft zweifelhaft iiber ihre Lage sein. Ich bin der Ansicht, dass diese Geästkerne der Endapparate markloser Nerven sowohl epilemmal als hypolemmal gelagert sein können.

Auf die Muskelspindeln des Frosches gründete Weismann seine Lehre von der Neubildung der Muskelfaser durch Zweitheilung. Diese Auffassung hat unter den Autoren Anklang gefunden; Kölliker ${ }^{1}$ ), Frey ${ }^{2}$ ) und $\mathrm{Krause}^{3}$ ) acceptiren sie. Letzterer

1) 1. c. p. 174 .
2) 1. c. p. 327.
3) 1. c. p. 499. 
behauptet, dass die Vermehrung der Muskelfasern dadurch geschehe, dass die Nervenfaser der Endplatte wuchere. Nach meiner Darstellung nun handelt es sich bei den Muskelspindeln des Frosches nicht um eine Abspaltung bereits differenzirten, quergestreiften Gewebes, sondern um Bildung neuer protoplasmatischer Massen, welche sich erst abspalten und dann weiter differenziren.

Weismann ${ }^{1}$ ) beschreibt, ohne jedoch die zugehörigen Nerven gesehen zu haben, die schon früher von Kölliker gesehenen Muskelspindeln des Frosches in folgender Weise: „Nicht selten sind solche Gruppen feiner (Muskel-) Fasern in der Mitte ihrer Länge in einer mehr oder minder langen Strecke zu einem Strang verbunden, und zwar erscheinen sie hier oft wie eingehüllt von einer matten, körnigen Substanz, durch welche hindurch man undeutlich die einzelnen Fasern verfolgen kann. Nicht selten liegen an solchen Stellen kleine Kerne in dicht gedrängten Gruppen innerbalb der Fasern."

Allerdings fällt ihm die Umhiullungsmasse auf, ,welche sich fast constant an dem Vereinigungspunkte der Fasern vorfindet, dieselben scheinbar zusammenhält und dem Blicke mehr oder weniger entzieht." Diese Umhüllungsmasse ist eben jene Ausbreitung der bindegewebigen Nervenscheide. Auch die ,kolbige Masse granulirter, grobkörniger Marterie und die spindelförmigen Zellen des Bindegewebes, welche im Verein mit Capillaren diese Stelle umbtillen", sind ihm auffällig. Auf eben jene grobkörnige Masse, welche, wie ich nachgewiesen habe, Protoplasma, nicht aber Fett ist, gründet er die Behauptung von einem Zugrundegehen der Mutterfaser.

Auch v. Wittich ${ }^{2}$ ) seheint durch diese Protoplasmamassen zu der Annahme veranlasst worden zu sein, dass eine Neubildung von Muskelfasern unter gleichzeitiger fettiger Degeneration der vorhandenen Fasern stattfinde. Diese Ansicht scheint heututage allgemein als Axiom betrachtet zu werden, wenigstens was die Batrachier anbetrifft.

Nach meinen Untersuchungen aber findet eine physiologisehe Fettdegeneration von Mnskelfasern nicht statt.

Als wahrscheinlich muss ich die Neubildung von Capillaren

1) 1. c. p. 269 .

2) Königsberger Jahrbücher Bd. III p. 46. 
Ueber die Muskclspindelı sowie Bemerkungen ïber Structur etc. 351

bezeichnen, die ich allerdings nicht direct beobachtet habe. Bei den Muskelspindeln fiel mir öfters der innige Zusammenhang auf, in welchem Capillaren mit diesen Gebilden stehen.

\section{Das Sarcolemm.}

Weder ist das Sarcolemm der ausgewachsenen Muskelfaser mit Kölliker als Zellmembran aufzufassen, welche unter Verlängerung der Faser weiter wächst, noch ist es, wie andere Autoren wollen, eine Bindegewebsauflagerung aus dem Perimysium internum. Bei der jungen, noch nicht innervirten Faser entspricht es allerdings der Zellmembran, oder vielmehr den untereinander verschmolzenen Membranen vieler Zellen, d.h. der Muskelkörperchen. Bei älteren, innervirten Muskelfasern dagegen kommt zu dem structurlosen Sarcolemm auf eine erhebliche Strecke zu beiden Seiten von der Einmuindungsstelle des Nerven noch die Ausbreitung der Henle'schen Scheide. Das Sarcolemm ist also auf eine gewisse Strecke eine mehrschichtige Membran. Hin und wieder gelingt es atrophirende Kerne in ibr nachzuweisen, die ursprunglichen Kerne der Henle'schen Scheide.

Ewald ${ }^{1}$ ) beschreibt an Silberbildern constant vorkommende kleinere ovale weisse Flecken mit feinen, mitunter verzweigten Ausläufern, welche theils parallel, theils schräge, ja sogar senkrecht zur Muskelfaser gestellt sind. Goldpräparate scheinen sich nicht besonders zur Darstellung dieser Kerne zu eignen. Von Silberpräparaten habe ich keine Erfahrung. Jedenfalls aber handelt es sich an den Bildern und in der Beschreibung um wirkliche Sarcolemm- und nicht um Muskelkerne.

Tannhofer ${ }^{2}$ ) fand mittelst des Verdaungsverfahrens, dass das Sarcolemm aus separaten Platten besteht. Die äussere bezeichnet er als byalin; sie besitzt selten Kerne, und dann nur wenige. Er nennt sie die äussere oder hyaline Membran des Sarcolemms. Hier wäre also anatomisch der Beweis gebracht von dem, was ich entwick-

1) Ueber die Endigung, der motor. Nerven in den quergestr. Muskeln. Pfiürer's Archiv Bd. XII p. 539.

2) Beiträge zur Histologie der Nervenendigungen der quergestreiften Muskeln. Dieses Archiv Bd. XXI 1. Heft S. $27 \mathrm{ff}$. 
lungsgeschichtlich auseinander gesetzt habe. Ich selbst habe, da ich das Verdauungsverfahren nicht anwendete, die verschiedenen Lamellen des Sarcolemms an ausgewachsenen Muskeln nie gesehen, sondern stets nur an Muskelspindeln. Wenn man so will, besteht das Sarlolemm eigentlich aus drei Membranen, nämlich der bindegewebigen Ausbreitung der äusseren Lamelle, dann der inneren Lamelle der Hen le'schen Scheide und endlich dem eigentlichen Sarcolemm. Dass der Nerv durch die Endplatte nicht unmittelbar mit der Muskelsubstanz in Verbindung steht, da er durch eine kernige membranartige Lamelle von dieser geschieden sei, wie Tannhofer behauptet (pag. 32), und dass in den Muskeln des Frosches sich der Nerv zwischen den beiden Lamellen des Sarcolemma ausbreite und eine Endplatte an der inneren kernigen Lamelle des Sarcolemma bilde (pag. 35), steht in scharfem Contrast zu den von mir geschilderten entwicklungsgeschichtlichen Vorgängen.

\section{Die Muskelspindeln der Maus}

sind schon genau von $K \ddot{u} h n e$ beschrieben und abgebildet worden. Auch hier handelt es sich, wie beim Froseh, um zusammengesetzte Spindeln, an denen die im Innern vorgehenden Wachsthumsveränderungen schwer erkennbar sind. Dagegen war ich durch sie befähigt, Aufschluss über die eigenthümliche Kerntheilung in den jungen wachsenden Muskelfasern zu erlangen (Figg. 25 und 25A).

Für den Fall, dass es bezweifelt werden möchte, dass man es bei den Muskelspindeln in der That ausschliesslich mit Wachsthums- nicht aber mit degenerativen Processen zu thun habe, habe ich eine ältere Muskelspindel abgebildet (Fig. 26), in welcher die im Werden begriffenen Endplatten sich zeigen. Das Ganze ist noch durch die provisorische bindegewebige Hülle eingeschlossen. Wie beim Frosche, treten hier oft eine grössere Anzahl von Nerven zu einem Strange vereinigt ein.

Die bündelweise Versorgung der Muskelfasern mit Nervenapparaten erklärt auch die Thatsache, dass man die letzteren fast immer gruppenweise zusammen trifft. Auch dies habe ich durch eine Abbildung dargestellt und zwar nach einem sehr gut gelungenen Goldpräparate (Fig. 27).

Charakteristische Nervenapparate von feinen markhaltigen 
Ueber die Muskelspindeln sowic Bemerkungen über Structur etc. 353

(II. Ordn.) oder marklosen Nerven, denen bei der Eidechse und dem Frosche vorkommenden entsprechend, habe ich im Muskel der Maus nicht aufzufinden vermocht. Dagegen fand ich sehr kleine Endplatten als Endigungen feiner markhaltiger Nerven, die sich aber in der Form nicht wesentlich von den als motoriseh anerkannten unterschieden. Marklose Nervenfasern scbeint es ausser an den Gefässen, im Muskel der Maus nicht zu geben.

In Vorstehendem habe ich versucht, die Genesis der Nervenendapparate im quergestreiften Muskel zu geben. Die vorliegende Frage spielt also in die Entwicklungsgeschichte hinüber und widerlegt, wie mir scheint eine Auffassung, die seiner Zeit so grosses Aufsehen erregt hat. „Hens en nimmt bekanntlich an, dass die Nervenzellen der Centraltheile und die peripherischen Endorgane, in denen die Nervenfasern enden, die er in erster Linie iiberall als Zellen sich denkt (Muskelzellen, sensible Endzellen), von den allerfrïhesten Zeiten der embryonalen Entwicklung an untereinander in Verbindung sind und in steter Verbindung bleibend weiter wuchern, wobei beliebig oft wiederkehrende Zellentheilungen und Spaltungen der Verbindungsfäden desselben, ohne oder mit Trennung der betreffenden Theile, jede nöthige Menge von Zellen und Fasern und jeden Verästelungstypus der letzteren zu erklären geeignet wären"1). Der Vereinigungsprocess der vorher von einander getrennten Muskelfasern und Nerven, wie ihn die Muskelspindel zu beobachten Gelegenheit bietet, spricht nicht für Hensen. Ebenso sprechen die Resultate meiner Beobachtungen (natürlich nur für das postembryonale Wachsthum) gegen die Kölliker'sche Lehre, ,dass die motorischen Nervenfasern mit ihren Axencylindern aus den Nervenzellen des Markes hervorwachsen und ununterbrochen bis in die Peripherie wuchern, während ibre kernhaltigen Scheiden einer Umhüillung der Axencylinder mit peripherischen Zellen ibren Ursprung verdanken"2). Die principielle Frage, ob ein Nerv in oder mit einer Zelle endige, wie Walả eyer sich aus-

1) Kölliker, Entwickelungsgesch. p. 602 .

2) Ebendaselbst p. 601 . 
druickt' ), ist dahin zu beantworten, dass die Endigung in, resp. a n einer Zelle stattfindet. Der Nerv sucht die Muskelzelle a uf und vereinigt sich mit ihr. Somit wüde also die Kleinenberg'sche Behauptung, die.von Gerlach anatomisch zu begründen gesucht wurde, dass die Muskelfaser als contractile Endausbreitung des Nerven aufzufassen sei, in strengem Wortsinne nicht aufrecht $\mathrm{zu}$ erhalten sein, wenn auch eine Verwachsung zwischen Nerv und demjenigen Protoplasma, welches die contractile Substanz aus sich herausbildet, an einer begrenzten Stelle stattfindet.

Vorliegende Arbeit ist das Resultat einer Reihe von Untersuchungen, welche im Winter 1881-1882 im Strassburger anatomischen Institute begonnen und später zu Ende geführt wurden.

\section{Erklärung der Figuren auf Tafel XII und XIII.}

Fig. 1. Eine Muskelfaser aus dem M. Sterno-radialis des Frosches, die Protoplasmaverbindungen der Muskelkörperchen und ihren allmähligen Uebergang in Muskelstäbchen zeigend.

Fig. 2. a Ebendaher; ein Muskelkörperchen mit Fortsatz isolirt; b maschenartige Verbindung der dicken Fäden; dazwischen die dünnen; c Querschnitt einer Muskelfaser aus dem Pectoralis major der Maus mit Punkten in den Cohnheim'schen Feldern (alles Goldschorid); a Querschnitt einer Muskelfaser von Hydrophilus piceus mit denselben Punkten. Osmium-Goldpräparat. e Theil einer Muskelfaser aus dem M. Sterno-radialis der Maus mit Reihen grober und feiner Fäden; f Schema der nicht geschrumpften, g der geschrumpften, groben Stäbchen; H Hensen'sche Linie, K Krause'sche Linic.

Fig. 3. Muskelfaser aus dem Triceps femoris von Lacerta muralis, mit Kernsäule.

Fig. 4. Muskelfaser aus dem Pectoralis major der Maus, die beginnende Muskelkörperchenkette aufweisend.

Fig. 5. Ebendaher, ein vorgerïckteres Stadium darstellend.

) Dieses Archiv XVII. 367. 
Ueber die Muskelspindeln sowie Bemerkungen äber Structur etc.

Fig. 6. Denselben Gegenstand illustrirend; Mnskelfaser aus der Zunge eines Kaninchens.

Fig. 7. Muskelspindel aus dem Schwanz von Lacerta muralis; frühstes Stadium. a Muskelkörperchen mit vergrössertem Protoplasmahofe, b äussere, c innere Lamelle der Henle'schen Scheide.

F'ig. 8. Dasselbe. Der Nerv $d$, nachdem er an einer Einschnürungsstelle (e) mit der Muskelfaser in Verbindung getreten ist, geht weiter, an der Faser entlang.

Fig.9u. 10. Dasselbe, das Stadium der Einschmelzung darstellend. Beide Spindeln mit Endapparaten markloser Nerven versehen (in b und c). In Fig. 10 setzt sich der markhaltige Nerv a mit der Spindel in Verbindung, Nerv b geht weiter, an der Muskelfaser entlang. Die marklose Faser des Endapparates bei c ist losgerissen.

Fig. 11. Junge Spindel, erste Kerntheilung darstellend. aa Muskelkerne, b äussere, c innere Lamelle der Henle'schen Scheide, d markloser Nerv mit Endapparat.

Fig. 12. Spindel mit zwei markhaltigen Nerven.

Fig. 13. Aeltere Spindel, in welcher sich schon eine Andentung einer Endplatte zeigt.

Fig. 14. Ganz junge Spindel. Bei a theilt sich der Nervenkern und bereitet sich eine Einschnürungsstelle vor.

Fig. 15. Spindel, welche den Vorgang bei der Verejnigung eines marklosen Nerven mit einer Muskelfaser darstellt.

Fig. 16. Spindel, Kerntheilung und Einschmelzung zeigend. Aus der Endplatte einer benachbarten Muskelfaser kommt ein markloser Nerv, welcher sich mit der Spindel in Verbindung setzt. Bei bb ist das contractile Gewebe vollständig eingeschmolzen.

Fig. 17. Endplatte, das gegenseitige Verhalten von Endfasern, Muskelkernen und Protoplasma zeigend.

Die Zeichnungen $7-17$ sind alle nach Präparaten aus den Schwanzmuskeln von Lacerta muralis angefertigt.

Fig. 18. Muskelspindel aus dem M. sterno-radialis des Frosches. Ausser einem Bündel dicker markhaltiger Nerven tritt ein dünner markhaltiger Nerv in die Spindel ein bei a.

Fig. 19. Muskelspindel eben daher mit einem markhaltigen Nerven mit lamellärer Bindegewebsscheide. Beide Spindeln zeigen deutlich die Umhüllungsscheide.

Fig. 20. Ein junges Endbüschel aus dem M. sterno-radialis des Frosches das Wesen der Besatzkörperchen klarlegend. aa die Besatzkörperchen (Muskelkörper).

Fig. 21. Eben daher, die Doldenform im Entstehen begriffen zeigend. Frühes Stadium mit vielem Muskelkörperchenprotoplasma. aa Besatzkörperchen (Muskelkerne), bei bb Haufen von Muskelkörperchen mit vorbereitenden Phasen zur Bildung der Fnddolde. 
Fig. 22. Typisches Endbüschel des Frosches mit aa Kernen der Schwann'* schen Scheide (Nervenkernen), bb Besatzkörperchen (Muskelkernen), cc Grundkernen (unregelmässig gelagerten Muskelkernen).

Fig. 23. Endapparat eines marklosen Nerven an einer Muskelfaser, das Verhältniss der hypolemmalen Fasern zu den Muskelkörperchen und ihren protoplasmatischen Verbindungsfäden darstellend, aaa gewöhnliche Muskelkerne, b unregelmässig gelagerter Muskelkern (Grundkern). c Kern der Schwann'schen Scheide (Nervenkern). M. sternoradialis, Frosch.

Fig. 24. Ein ähnlicher Endapparat im Profil an einem Fragment einer Muskelfaser. aa etc. Muskelkerne, bb Kerne der S ch wann'schen Scheide.

Fig. 25. Muskelspindel der Maus mit zwei Bündeln markhaltiger Nerven. In dieser zusammengesetzten Spindel liegt eine Einzelspindel, welche die Querstellung der Muskelkerne und ihre Theilung veranschaulicht.

F'ig. 25A. Eine Einzelspindel (Maus) mit Querstellung der Kerne. Die Theilung der Kerne hat bis jetzt nur in einer Richtung stattgefunden.

Fig. 26. Aeltere Muskelspindel der Maus. Die Endplatten sind im halbfertigen Zustande. Die gemeinsame Umhüllungsmembran ist noch vorhanden.

Fig. 27. Gruppe von fertigen Endapparaten. Die Gruppe entspricht ungefähr dem frei gewordenen Inhalte einer Spindel (Pectoralis der Maus).

\section{Ueber einige Färbungsmethoden, besonders für krankhafte Gewebe, mittelst Safranin und deren Resultate.}

Von

Dr. Victor Babes (iu)

aus Budapest.

Das Safranin ist das Chlorhydrat einer Base $\mathrm{C}_{21} \mathrm{H}_{20} \mathrm{~N}_{24}$ von unbekannter Constitution, vielleicht auch kein einheitlicher Körper. Derselbe nimmt eine $Z$ wischenstufe zwischen den eigentlichen Anilinfarbstoffen (Rosanilin) und dem Amidoazobenzol (Anilingelb) ein, aus welch letzterem und Echappé (ein Gemenge von Körpern verschiedener Flïchtigkeit der Toluidinreihe, deren flüchtigstes das Anilinöl ist) durch Oxydation mittelst Arsensäure oder Chrom- 